\title{
IMMEDIATE RESULTS OF PERCUTANEOUS TRANS-MITRAL COMMISSOROTOMY IN JUVENILE MITRAL STENOSIS
}

\author{
Ahsan Beg, Muhammad Younas*, Amjad Mahmood**, Mubashar Shervani*, Fakher-e-Fayaz ${ }^{* * *}$ \\ Quaid-e-Azam Medical College Bahawalpur Pakistan, *CPE Institute of Cardiology Multan Pakistan, **Armed Forces Institute of \\ Cardiology/National Institute of Heart Disease (AFIC/NIHD)/National University of Medical Sciences (NUMS) Rawalpindi Pakistan, \\ ${ }^{* * *}$ Army Cardiac Center Lahore/National University of Medical Sciences (NUMS) Pakistan
}

\begin{abstract}
Objectives: Immediate result of PTMC in juvenile (5-12 years) rheumatic mitral stenosis. Study Design: Observational descriptive and retrospective study. Place and Duration of Study: Institute of Cardiology, Multan from 2009 to Jun 2020. Methodology: This is an observational descriptive and retrospective study carried out at Institute of Cardiology, Multan from 2009 to Jun 2020. Patients with clinical evidence of significant mitral stenosis were undergone transthoracic echocardiography. Mitral stenosis was defined as mitral valve area $<1.0 \mathrm{~cm}^{2}$. Mean mitral valve gradient was calculated by mitral valve inflow velocities. Patients with Wilkins score $<8$ were included. Patients with significant MR, left atrial or atrial appendage clot, infective endocarditis, significant aortic regurgitation or any other indication for bypass surgery were excluded. Patients with Wilkins score $>8$ were also excluded from the study. Variables recorded on a performa were age, weight, left atrial size, mean mitral valve gradient, preprocedure MR. Reduction of mitral valve mean pressure gradients to less than $<50 \%$ of the initial value was defined as success (without significant or moderate MR). After the procedure, variables recorded on performa were mean left atrial pressures in mmHg (on angio), mean mitral valve gradients and degree of $\mathrm{MR}$ (mild, mild to moderate, moderate or severe MR) on transthoracic echocardiography. Paired t-test of significance $(p<0.05)$ was evaluated using SPSS (version 20).

Results: Forty three juvenile patients were included the in the study (2009 to June 2019). Mean age was $10.8 \pm 1.4$ (range 7-12) years. Mean weight was $28.9 \pm 5.2(20-37) \mathrm{kg}$. Mean mitral valve gradient (on TTE) before the procedure was $20 \pm 6 \mathrm{mmHg}$. Mean left atrial size and mean area of mitral valve were $42 \pm 5 \mathrm{~mm}$ and $0.8 \pm 0.2 \mathrm{~cm}^{2}$ respectively. Balloon sizes used were $26 \mathrm{~mm}(\mathrm{n}=19)$ and $24 \mathrm{~mm}(\mathrm{n}=24)$. After PTMC, mean mitral valve reduced to $7 \pm 2 \mathrm{mmHg}(p<0.005)$ and left atrial pressure to $18 \pm 7 \mathrm{mmHg}$. Post procedure transthoracic echocardiography showed $4.7 \%(n=2 / 43)$ patients developed moderate to severe or severe MR. So the success rate was $95.3 \%$ $(\mathrm{n}=41 / 43)$.

Conclusion: PTMC is safe and effective procedure for juvenile patients with mitral stenosis. Long term follow-up is needed to find out period of re-intervention/surgery free duration from the time of PTMC.
\end{abstract}

Keywords: Acute rheumatic fever, Juvenile mitral stenosis, PTMC, Percutaneous trans mitral commissorotomy, Rheumatic heart disease.

This is an Open Access article distributed under the terms of the Creative Commons Attribution License (http://creativecommons.org/licenses/by/4.0), which permits unrestricted use, distribution, and reproduction in any medium, provided the original work is properly cited.

\section{INTRODUCTION}

Acute rheumatic fever (ARF) is a result of body's autoimmune response to a throat infection caused by group A Streptococcus bacteria. Rheumatic heart disease (RHD) refers to the long-term cardiac damage caused by either a single severe episode or multiple recurrent episodes of ARF. RHD is worldwide cause of significant morbidity and mortality, particularly in resource-poor

Correspondence: Dr Ahsan Beg, Quaid-e-Azam Medical College, Bahawalpur Pakistan settings ${ }^{1}$. Globally, there were 33.4 million cases of RHD and 10.5 million disability-adjusted life years in year 2015 due to RHD. Pakistan is high risk country for RF and RHD2. Lack of education, poverty, over-crowding and lack of health facilities are contributing factors ${ }^{3}$. Commonest lesion with RHD is mitral regurgitation ${ }^{4}$. But over years, we have seen significant mitral stenosis (MS) in children as well 5-12, years of age).

Surgical commissorotomy was started in 1923 and became a standard treatment in late 
1940 's ${ }^{5}$. Inoue balloon catheter was introduced in 1984. Afterwards percutaneous balloon mitral valvotomy (PTMC) proved to be effective and safe $^{6,7}$. It is now standard treatment in selected patients with rheumatic mitral stenosis (MS). AHA/ACC has described PTMC as class I indication for rheumatic MS with favorable mitral valve (MV) morphology ${ }^{8}$. Several local authors have published their results in adults ${ }^{9-11}$. No local study has reported the immediate results in children (<12 years) with severe MS.

\section{METHODOLOGY}

This is an observational descriptive and retrospective study carried out at Institute of Cardiology, Multan from 2009 to June 2020. Pediatric patients (5-12 years) were evaluated by history, physical evaluation, $x$-ray chest PA view. Patients with clinical evidence of significant mitral stenosis were undergone transthoracic echocardiography (TTE) using 3S probe of Vivid 7 machine (GE healthcare, Norway). Operators were well trained for the assessment of RHD patients. Activity of the disease was ruled out by blood test (Normal ESR $<30 \mathrm{~mm}$ in 1st hr., ASOT titers $<240$ units).

The TTE was the main tool for look for suitable/favorable morphology of MV. Planimetry was used to calculate mitral valve area ${ }^{12}$. Mitral stenosis was defined as mitral valve area $<1.0 \mathrm{~cm}^{2}$. Mean mitral valve gradient (MVPG) was calculated by MV inflow velocities in 4 chamber apical view using continuous wave (CW) and pulse wave (PW). Pulmonary artery systolic flow (PAP) calculated from TR jet pressure gradient (TVPG) and right atrial pressure (RAP) whereas PAP $=$ TVPG \pm RAP. Planimetry was used to calculate mitral valve area. Patients with Wilkins score $<8$ were included ${ }^{13}$. Patients with significant MR, left atrial or atrial appendage clot, infective endocarditis, significant aortic regurgitation or any other indication for bypass surgery were excluded. Patients with Wilkins score $>8$ were also excluded from the study.

Variables recorded on a performa were age, weight, left atrial (LA) size, mean MV gradient, pre-procedure MR. After informed consent procedure performed in catheterization lab under local anesthesia using femoral venous approach ${ }^{14}$. Prophylactic antibiotics are started a day before the procedure. After sepal puncture, heparin was give 75 units $/ \mathrm{kg}$ intravenously. Inoue balloon (Toray International America. INC. Medical) was used in all cases (fig-2). Balloon size was calculated from the following equation.

Balloon size in $\mathrm{mm}=$ patients height in $\mathrm{cm} / 10$ \pm 10 . LA pressures (mean) are documented in $\mathrm{mmHg}$. First inflation was done $1-2 \mathrm{~mm}$ less than maximum diameter of the balloon. If results were suboptimal, balloon was inflated to the maximum

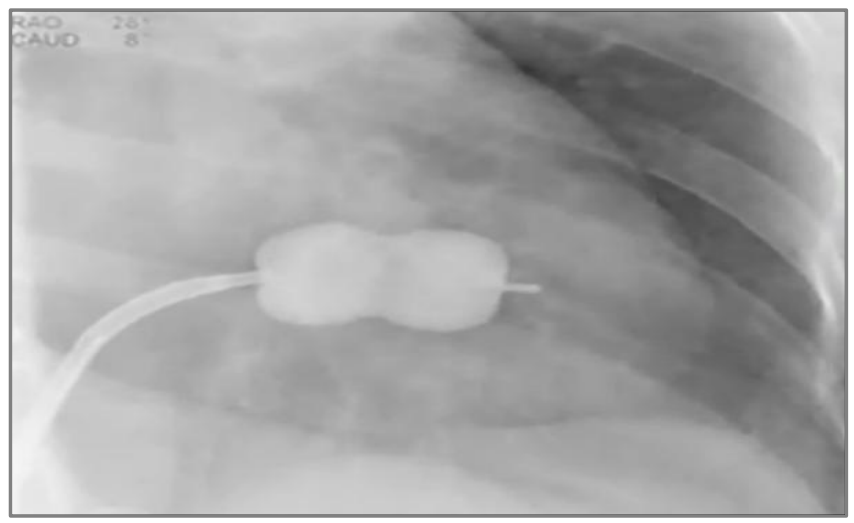

Figure-1: Inoue balloon inflated across MV.

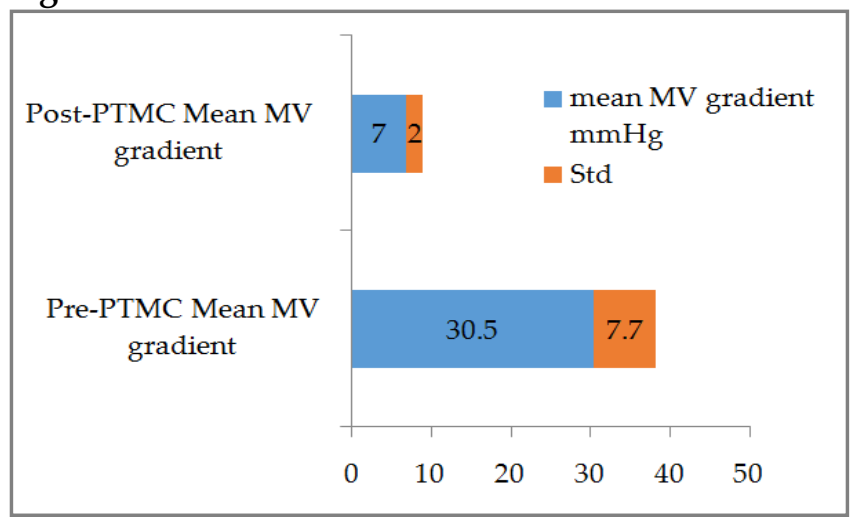

Figure-2: MV mean pressures (before and after PTMC).

estimated diameter. Reduction of LA pressure to less than $<50 \%$ of the initial value was defined as success (without significant MR (i.e. moderate MR).

Transthoracic echocardiography (TTE) was performed next day to the procedure for mean 
MV gradients and MR. Patients who developed severe MR (failure of the procedure) were referred for surgical MV replacement.

After the procedure, variables recorded were mean LA pressures in $\mathrm{mmHg}$ (on angio), mean MV gradients and degree of MR (mild, mild to moderate, moderate or severe MR) on TTE. Paired t-test of significance $(p<0.05)$ was evaluated using SPSS (version 20).

\section{RESULTS}

Forty three juvenile patients were included the in the study (2009 to June 2019). Mean age

Table: Data and hemodynamics (no, percentages, means and standard deviation).

\begin{tabular}{l|c}
\hline Total PTMC performed & $\mathrm{n}=71$ \\
\hline Incomplete data & $\mathrm{n}=28$ \\
\hline $\begin{array}{l}\text { Total patients included in } \\
\text { the study }\end{array}$ & $\mathrm{n}=43$ \\
\hline Male: Female & $21: 23$ \\
\hline Mean age (years) & $10.8 \pm 1.4($ range $7-12)$ \\
\hline Mean weight (in kg) & $28.9 \pm 5.2(20-37) \mathrm{kg}$ \\
\hline $\begin{array}{l}\text { Pre-PTMC Mean MV } \\
\text { gradient (mmHg) }\end{array}$ & $30.5 \pm 7.7 \mathrm{~mm} \mathrm{Hg}$ \\
\hline $\begin{array}{l}\text { Post-PTMC Mean MV } \\
\text { gradient (mmHg) }\end{array}$ & $7 \pm 2 \mathrm{mmHg}$ \\
\hline $\begin{array}{l}\text { Pre-PTMC Mean LA } \\
\text { pressures (mmHg) }\end{array}$ & $30 \pm 7 \mathrm{mmHg}$ \\
\hline $\begin{array}{l}\text { Post-PTMC Mean LA } \\
\text { pressures (mmHg) }\end{array}$ & $19 \pm 7 \mathrm{mmHg}$ \\
\hline Pre- mean LA size (mm & $42 \pm 5 \mathrm{~mm}$ \\
\hline Pre- mean MV area $\left(\mathrm{cm}^{2}\right)$ & $0.8 \pm 0.2 \mathrm{~cm}{ }^{2}$ \\
\hline $\begin{array}{l}\text { Balloon size used } \\
\mathrm{mm}(\mathrm{n}=19)\end{array}$ \\
\hline $\begin{array}{l}\text { Success rate } \\
\text { Complication rate } \\
\text { (>moderate MR) }\end{array}$ & $95.3 \%(\mathrm{n}=41 / 43)$ \\
\hline $\begin{array}{l}\text { Death / cardiac } \\
\text { perforation }\end{array}$ & $4.7 \%(\mathrm{n}=2 / 43)$ \\
\hline $\begin{array}{l}\text { Pre-existing atrial } \\
\text { tachyarrhythmia }\end{array}$ & - \\
\hline $\begin{array}{l}\text { Significant bleed }(\mathrm{and} \\
\text { transfusion) }\end{array}$ & - \\
\hline
\end{tabular}

was $10.8 \pm 1.4$ (range 7-12) years. Mean weight was $28.9 \pm 5.2$ (20-37) kg. Mean MV gradient (on TTE) before the procedure was $20 \pm 6 \mathrm{mmHg}$.
Mean LA size and mean area of MV were $42 \pm 5$ $\mathrm{mm}$ and $0.8 \pm 0.2 \mathrm{~cm}^{2}$ respectively (table).

Balloon sizes used were $26 \mathrm{~mm}(\mathrm{n}=19)$ and $24 \mathrm{~mm}(\mathrm{n}=24)$. After PTMC, mean MV reduced to $7 \pm 2 \mathrm{mmHg}(p<0.005)$ and LA pressure to $18 \pm 7$ $\mathrm{mmHg}$ fig-1. Post procedure TTE showed $4.7 \%$ $(n=2 / 43)$ patients developed moderate to severe or severe MR. So the success rate was $95.3 \%$ $(n=41 / 43)$. We did not any cardiac perforation or death. No patient had significant bleeding.

\section{DISCUSSION}

Developed world has low prevalence of RHD (1 in as 100000 for Unites States). However developing countries are endemic (estimated childhood mortality due to RHD $>0.15$ deaths per 100,000 population among children 5 to 9 years of age) 2 Commonest cause of valvular heart disease in Pakistan is RHD ${ }^{3}$. Risk factors for RHD (Overcrowding, poor hygienic conditions, low socioeconomic status, and illiteracy) remain unchanged over years in Pakistan ${ }^{3}$. This leads to rheumatic mitral stenosis even in juvenile patients (512 years).

PTMC is effective therapy for mitral stenosis. Severe authors have reported the results in adult patients $9,10,11$. However none of local experience for juvenile patients is not reported. Authors from India (age <20 years) and Africa (age <21 years) has reported results in juvenile patients 15,16 . The age groups in these studies were $<20$ years or $<21$ years. The success is dependent on multiple factors including preexisting MR, Wilkins scoring. Our success rate was $95.3 \%$. Our results are parallel to other studies ${ }^{17}$. One local study conducted at Peshawar showed procedural success in $96 \%$ patients ${ }^{18}$.

Most important complication is increase of severity of MR. Reports documented frequency of severe MR varies from $2 \%$ to $19 \% 19$. Two of patients developed severe MR which was referred for surgical MV replacement. Factors which lead to severe MR remain controversial ${ }^{20}$, fic 25 It could be due to tear of anterior or posterior leaflets. Frequency of atrial septal defect has not been evaluated in our study. Other authors have 
reported frequency from $10-90 \%$. But these are small residual shunts. Long term follow-up is needed to find out period of re-intervention/ surgery free duration from the time of PTMC.

The restenosis is defined as reduction of MV area by $50 \%$ compared to post PTMC MV area. Re-stenosis is not documented in our study. Trestenosis rate after PTMC has ranged from 3\% to $70 \%$ at 1 to 3 years ${ }^{21}$.

\section{CONCLUSION}

PTMC is safe and effective procedure for juvenile patients with mitral stenosis. Long term follow-up is needed to find out period of reintervention/surgery free duration from the time of PTMC.

\section{CONFLICT OF INTEREST}

This study has no conflict of interest to be declared by any author.

\section{REFERENCES}

1. Karthikeyan G, Guilherme L. Acute rheumatic fever. Lancet 2018; 392(10142): 161-74.

2. Watkins DA, Johnson CO, Colquhoun SM, Karthikeyan G, Beaton A, Bukhman G, et al. Global, Regional, and National Burden of Rheumatic Heart Disease, 1990-2015. N Engl J 2017; 377(8): 713-22.

3. Beg DA, Younas DM, Asma Ch DT. Rheumatic Heart Disease (Rhd); Socio-Economic And Environmental Risk Factors For Acute Rheumatic Fever (Arf) And Rheumatic Heart Disease (Rhd) Patients In Pakistan. Prof Med J 2006; 23(3): 324-27.

4. Russell EA, Walsh WF, Costello B, Mc Lellan AJA, BrownA, Reid CM, et al. Medical Management of Rheumatic Heart Disease. Cardiol Rev 2018; 26(4): 187-95.

5. Noohi F, Sadeghpour A, Alizadehasl A. Valvular Heart Disease. In Practical Cardiology (pp. 395-441). 2018 Elsevier. [INternet] https://doi.org/10.1016/b978-0-323-51149-0.00025-0.

6. Tawn Z, Himbert D, Brochet E, Messika-Zeitoun D, Iung B, Vahanian A. Percutaneous valve procedures: present and future. Int J Cardio Inter 2005; 7(1): 14-20.

7. Vahanian A, Acar C. Percutaneous valve procedures: what is the future?. Curr Opin Cardiol 2005; 20(2): 100-06.

8. Nishimura RA, Otto CM, Bonow RO, Carabello BA, Erwin JP,
Fleisher LA, et al. AHA/ACC Focused Update of the 2014 AHA/ACC Guideline for the Management of Patients With Valvular Heart Disease. J Am Coll Cardiol 2017; 70(2): 252-89.

9. BABAR HAK, SAAD AA, BUTT ZR, KHAN Z, DASTGEER S, IQBAL MM. Severe mitral stenosis; in-hospital outcomes of percutaneous transvenous mitral commissurotomy (ptmc) in patients. Prof Med J 2017; 24(6): 850-54.

10. Walia T, Bhardwaj P, Chaudhury S, Aneja A, Jetley V, Mujawar $\mathrm{S}$. Assessment of quality of life before and after successful percutaneous transvenous mitral commissurotomy in patients with severe mitral stenosis. Indust Psy J 2019; 28(1): 51-57.

11. Ali L, Asghar N, Riaz R, Hussain M. Percutaneous transmitral commissurotomy (PTMC); Procedural success and immediate results, a tertiary care hospital experience from developing country. Prof Med J 2016; 23(1): 104-13.

12. Cheitlin MD, Alpert JS, Armstrong WF, Aurigemma GP, Beller GA, Bierman FZ. ACC/AHA Guidelines for the Clinical Application of Echocardiography. Circulation, 1997; 95(6): 1686-44.

13. Wilkins GT, Weyman AE, Abascal VM. Percutaneous balloon dilatation of the mitral valve: an analysis of echocardiographic variables related to outcome and the mechanism of dilatation. $\mathrm{Br}$ Hear J 1988; 60(4): 299-08.

14. Vahanian A, Luxereau P, Brochet E, Cormier B, Iung B. Percutaneous mitral commissurotomy: technique, results, and selection of patients. Przeglad Lekarski 2004; 61(6): 543-46.

15. Adhikari CM, Malla R, Rajbhandari R. Percutaneous transvenous mitral commissurotomy in juvenile mitral stenosis. Cardiovasc Diagn Ther 2016; 6(1): 20-24.

16. Yonga GO, Bonhoeffer P. Percutaneous transvenous mitral commissurotomy in juvenile mitral stenosis. East Afr Med J 2003; 80(4): 172-74.

17. Dawood S, Karim MR. Haq M, Ali M, Chowdhury MZ. Percutaneous transvenous mitral commissurotomy. in- hospital outcome of patients with mitral stenosis. Ibrahim Card. Med J 2011; 1(2): 24-28.

18. Khan SB, Ali J, Zeb RS, Irfan M, Gul AM. Percutaneous Commissurotomy (PTMC): Procedural Success and Immediate Results. PJC 2013; 24(1\&2): 5-10.

19. Varma PK, Theodore S, Neema PK, Ramachandran P, Sivadasanpillai $\mathrm{H}$, Nair KK, et al. Emergency surgery after percutaneous transmitralcommissurotomy: operative versus echocardiographic findings, mechanisms of complications, and outcomes. J Thorac Cardiovasc Surg 2005; 130(3): 772-76.

20. Essop MR, Wisenbaugh T, Skoularigis J, Middlemost S, Sareli P. "Mitral regurgitation following mitral balloon valvotomy. Differing mechanisms for severe versus mild-tomoderate lesions," Circulation 1991; 84(4): pp.1669-79.

21. Sriram MJ, Venkata BJ, Sadagopan T, Ramamurthy MT. Immediate, intermediate and long term clinical outcomes of percutaneous transvenous mitral commissurotomy. IJC Heart Vascul 2015; 6(1): 66-70. 